\title{
OS NÍVEIS DE ANÁLISE LINGUÍSTICA E A ENUNCIAÇÃO: A AVALIAÇÃO NA CLÍNICA DOS DISTÚRBIOS DE LINGUAGEM
}

\author{
Suziane Fernanda Klein \\ Jefferson Lopes Cardoso
}

Submetido em 24 de maio de 2018.

Aceito para publicação em 24 de agosto de 2018.

Cadernos do IL, Porto Alegre, n. ${ }^{\circ}$ 56, mês de novembro. p. 131-146

\section{POLÍTICA DE DIREITO AUTORAL}

Autores que publicam nesta revista concordam com os seguintes termos:

(a) Os autores mantêm os direitos autorais e concedem à revista o direito de primeira publicação, com o trabalho simultaneamente licenciado sob a Creative Commons Attribution License, permitindo o compartilhamento do trabalho com reconhecimento da autoria do trabalho e publicação inicial nesta revista.

(b) Os autores têm autorização para assumir contratos adicionais separadamente, para distribuição não exclusiva da versão do trabalho publicada nesta revista (ex.: publicar em repositório institucional ou como capítulo de livro), com reconhecimento de autoria e publicação inicial nesta revista.

(c) Os autores têm permissão e são estimulados a publicar e distribuir seu trabalho online (ex.: em repositórios institucionais ou na sua página pessoal) a qualquer ponto antes ou durante o processo editorial, já que isso pode gerar alterações produtivas, bem como aumentar o impacto e a citação do trabalho publicado.

(d) Os autores estão conscientes de que a revista não se responsabiliza pela solicitação ou pelo pagamento de direitos autorais referentes às imagens incorporadas ao artigo. A obtenção de autorização para a publicação de imagens, de autoria do próprio autor do artigo ou de terceiros, é de responsabilidade do autor. Por esta razão, para todos os artigos que contenham imagens, o autor deve ter uma autorização do uso da imagem, sem qualquer ônus financeiro para os Cadernos do IL.

\section{POLÍTICA DE ACESSO LIVRE}

Esta revista oferece acesso livre imediato ao seu conteúdo, seguindo o princípio de que disponibilizar gratuitamente o conhecimento científico ao público proporciona sua democratização.

http://seer.ufrgs.br/cadernosdoil/index

Quinta-feira, 22 de novembro de 2018. 


\title{
OS NÍVEIS DE ANÁLISE LINGUÍSTICA E A ENUNCIAÇÃO: A AVALIAÇÃO NA CLÍNICA DOS DISTÚRBIOS DE LINGUAGEM
}

\author{
THE LEVELS OF LINGUISTIC ANALYSIS AND \\ ENUNCIATION: THE EVALUATION ON LANGUAGE \\ DISORDERS CLINICS
}

\author{
Suziane Fernanda Klein* \\ Jefferson Lopes Cardoso**
}

\begin{abstract}
RESUMO: Este trabalho é construído por meio do diálogo entre a Linguística da Enunciação e a Clínica dos Distúrbios de Linguagem. A partir de conceitos extraídos da Teoria Enunciativa benvenistiana o enfoque do estudo recai sobre a análise de linguagem. O delineamento é qualitativo retrospectivo e os objetivos são: refletir sobre a noção de nível de análise linguística e suas implicações na avaliação de linguagem; realizar uma discussão acerca da avaliação na clínica de linguagem fonoaudiológica; mostrar e descrever a imbricação dos níveis da língua em um caso de Distúrbio de Linguagem. Conclui-se que a noção de nível de análise linguística, voltada à enunciação, pode subsidiar uma análise de linguagem que contemple a relação língua-falante na Clínica dos Distúrbios de Linguagem.
\end{abstract}

PALAVRAS-CHAVE: Fonoaudiologia; Linguística da Enunciação; Clínica dos Distúrbios de Linguagem; Avaliação de Linguagem.

ABSTRACT: This work is built through the dialogue between Enunciation Linguistics and the Language Disorders Clinic. From concepts drawn from Benvenistian enunciative theory the focus of the study lies on language analysis. The design is qualitative retrospective and the objectives are: to reflect on the notion of linguistic analysis level and its implications in the evaluation of language; to conduct a discussion about assessment in speech language pathology clinic; show and describe the imbrication of language levels in a case of Language Disorder. It is concluded that the notion of linguistic analysis level, aimed at enunciation, can subsidize a language analysis that contemplates the speaker-language relationship in the Language Disorders Clinic.

KEYWORDS: Speech, Language and Hearing Sciences; Enunciation Linguistics; Language Disorders Clinic; Language Evaluation.

\section{Introdução}

A avaliação de linguagem é vista como marca de início das intervenções fonoaudiológicas nos casos de distúrbio de linguagem ${ }^{1}$. Por meio dela são colhidas informações e formuladas hipóteses que guiarão o desenvolvimento de todo o processo terapêutico. Dessa forma, a avaliação configura-se como um instrumento extremamente

\footnotetext{
*Fonoaudióloga pela Universidade Federal do Rio Grande do Sul, suzianeklein@ gmail.com.

** Professor Adjunto do curso de Fonoaudiologia da Universidade Federal do Rio Grande do Sul, doutor em Linguagem pela Universidade Federal do Rio Grande do Sul, jeflcardoso@ @otmail.com.

${ }^{1} \mathrm{O}$ distúrbio de linguagem, neste trabalho, é definido como "o conjunto das manifestações de linguagem de um sujeito que comparecem na instância clínica" (CARDOSO, 2010, p. 20).
} 
importante, e o terapeuta, desde o momento que avalia, é subsidiado por uma rede teórica de conceitos que norteará todo o seu fazer clínico.

Considerando-se a relevância do processo de avaliação na Clínica dos Distúrbios de Linguagem ${ }^{2}$, este trabalho apresentará uma proposta de análise de linguagem embasada na noção de nível de análise linguística formulada por Émile Benveniste. Nessa direção, os objetivos deste trabalho são: refletir sobre a noção de nível de análise linguística e suas implicações na avaliação de linguagem na clínica; realizar uma discussão acerca da avaliação na clínica fonoaudiológica de linguagem e mostrar e descrever a imbricação dos níveis da língua em um caso de Distúrbio de Linguagem. Destaca-se que o termo imbricação foi empregado para referir-se à integração e interdependência existente entre os níveis linguísticos descritos por Benveniste (1989).

Para atingir os objetivos formulados, faz-se necessário um percurso teórico que iniciará com a exposição de aspectos da Teoria Enunciativa benvenistiana, enfatizandose a noção de nível de análise linguística. Em seguida, serão apontados alguns estudos realizados com embasamento na Teoria da Enunciação e, logo após, se discutirá o processo de avaliação na clínica fonoaudiológica, por meio de uma breve retomada de abordagens teóricas e de aspectos relacionados a essa instância clínica. Na seção intitulada metodologia se esclarecerá o delineamento desse trabalho e, na sequência, se terá a apresentação e análise dos dados coletados. Para finalizar, se mostrará a discussão e as conclusões do estudo.

\section{Fundamentação teórica}

\subsection{A Teoria Enunciativa e os níveis da análise linguística}

A Teoria da Enunciação constitui um campo da linguística voltado para o estudo semântico da língua. Muitos estudiosos apresentam trabalhos nessa área, fato que origina concepções distintas acerca de um mesmo objeto, a enunciação. Segundo Flores e Teixeira (2005), apesar das divergências, há pontos em comum entre esses estudiosos, como a discussão do pensamento do linguista Ferdinand de Saussure, a definição do termo enunciação e o estabelecimento de relações distintas entre a linguística e a filosofia da ciência. Considerando-se as vertentes teóricas originadas desse campo da linguística, elegeu-se a Teoria Enunciativa de Émile Benveniste ${ }^{3}$ para embasar o presente estudo.

A Teoria Enunciativa benvenistiana possui um amplo arcabouço teórico, constituído por uma rede de conceitos interligados. Por esse motivo, é difícil propor a abordagem de somente um conceito da teoria. Sabendo-se dessa dificuldade, elegeu-se como foco central a noção de nível de análise linguística estudada por Benveniste. Os conceitos que estão associados a essa noção central serão abordados de uma forma mais sucinta, porém isso não indica que sejam menos importantes. Trata-se apenas de uma decisão teórico-metodológica.

Diante da extrema complexidade da linguagem, Benveniste (1989) reconhece a necessidade de sua descrição como uma estrutura formal. Em termos de análise, ele enfatiza que, antes de tudo, é fundamental o estabelecimento de procedimentos e

\footnotetext{
${ }^{2}$ O conceito presente no sintagma Clínica dos Distúrbios de Linguagem será explicitado no item 2.3.

${ }^{3}$ Émile Benveniste é considerado o principal representante das Teorias da Enunciação.
} 
critérios adequados. Foi assim que o linguista elegeu a noção de nível como essencial para determinar-se o procedimento de análise:

só ela é própria para fazer justiça à natureza articulada da linguagem e ao caráter discreto dos seus elementos; só ela pode fazer-nos reconhecer, na complexidade das formas, a arquitetura singular das partes e do todo (BENVENISTE, 1989, p. 127).

Para o autor, o procedimento inteiro da análise tende a delimitar os elementos por meio das relações que os unem. Ao mencionar a técnica de análise distribucional, Benveniste (1989) destaca as duas operações que a constituem: a segmentação e a substituição. Essas operações, que integram o método distribucional, colocam em evidência uma relação dupla de funcionamento da língua. Essa relação, estudada originalmente por Ferdinand de Saussure, considera os dois eixos aos quais os elementos linguísticos estão submetidos: sintagma e paradigma. Segundo Benveniste (1989, p. 128), a relação sintagmática compreende a "[...] relação do elemento com os outros elementos simultaneamente presentes na mesma porção do enunciado [...]", enquanto a relação paradigmática é a "relação do elemento com os outros elementos mutuamente substituíveis". É por meio da relação paradigmática que se selecionam e se substituem os signos virtuais da língua, e a sua combinação é possível pela relação sintagmática, que os associa. Trata-se de duas relações interligadas e interdependentes.

Em relação às operações de segmentação e de substituição, dois destaques são importantes. O primeiro é sobre o fato de que elas não possuem o mesmo alcance. A segmentação só é possível até o nível fonemático da língua, enquanto a substituição pode ir até um nível mais inferior, o merismático. Com base nisso, tem-se duas classes de elementos mínimos ou inferiores numa análise: os fonemas (segmentáveis e substituíveis) e os merismas ou traços distintivos (apenas substituíveis). Os merismas não podem compor classes sintagmáticas por não suportarem a segmentação, porém podem constituir classes paradigmáticas por permitirem a substituição (BENVENISTE, 1989). O segundo destaque é que as operações de segmentação e de substituição não podem ser empregadas em qualquer parte da cadeia falada, deve-se considerar que "uma unidade linguística só será recebida como tal se se puder identificar em uma unidade mais alta" (BENVENISTE, 1989, p. 131). Para esclarecer essa consideração pode-se citar o fonema, que só será concebido como unidade linguística ao constituir um nível maior, o do morfema. É necessário ter claro que os diferentes níveis da língua estão relacionados, questão não comportada na técnica de análise distribucional.

Benveniste (1989) ressalta que o método distribucional não põe em evidência essa relação entre níveis diferentes, pois considera na análise apenas um dos níveis da língua, não contemplando a imbricação existente entre eles. Para uma análise da língua é fundamental compreender a relação de transversalidade existente entre os níveis, porque "o nível não é exterior à análise, mas um operador dela" (FLORES, 2009, p. 184).

Seguindo o raciocínio de análise benvenistiano, avança-se do nível mais inferior, o merisma, passando-se pelo fonema e pelo morfema para, enfim, atingir-se um nível superior, o da palavra. A palavra pode ser decomposta em unidades fonemáticas, assumir o papel de unidade significante isolada ou, em conjunto com outras unidades, integrar um nível maior, o da frase. A frase concebe um todo não redutível à soma das partes. Em outros termos, a frase não pode ser compreendida como um somatório do sentido fornecido por cada palavra. A palavra constitui a frase, dando-lhe significação, 
porém, a frase, por ser de um nível maior, não comporta a palavra com o sentido que ela tem como unidade autônoma. Nas palavras de Benveniste (1989, p. 132), "a frase realiza-se em palavras, mas as palavras não são simplesmente os seus segmentos".

A transição entre os níveis da língua, de acordo com Benveniste (1989), suscita mudanças na articulação das unidades. Por isso, o autor ressalta duas formas de relação admitidas pelas entidades linguísticas: a relação distribucional e a integrativa. A primeira refere-se às relações entre os elementos de um mesmo nível, enquanto a segunda trata das relações entre níveis distintos. Benveniste $(1989$, p. 133) descreve que o signo é "materialmente função dos seus elementos constitutivos", porém a única forma de definir esses elementos é identificando-os na unidade em que assumem a função integrativa.

A distinção entre constituinte e integrante ocorre por dois limites: o da frase e o do merisma. A frase, configurada como limite superior, comporta constituintes, mas não pode integrar unidades mais altas. Já o merisma, limite inferior, não comporta constituintes de natureza linguística. Dessa forma, a frase só se define por seus constituintes e o merisma só se define como integrante.

Marcar a diferença entre constituinte e integrante tem uma função fundamental nas unidades de diferentes níveis: explicitar a relação entre a forma e o sentido. Segundo Silva (2007), Benveniste demarca a unidade de análise ponderando que as unidades de distintos níveis da língua precisam ser caracterizadas pela articulação entre forma e sentido. Devido a isso, "[...] a forma de uma unidade linguística define-se como a sua capacidade de dissociar-se em constituintes de nível inferior e [que] o sentido define-se como a sua capacidade de integrar uma unidade de nível superior" (SILVA, 2007, p. 218).

É dessa maneira que a noção de nível de análise linguística está relacionada às concepções de forma e sentido em Benveniste (1989). A forma de uma unidade linguística possibilita a sua dissociação, ou seja, a redução em constituintes de nível inferior, enquanto o sentido é o responsável por integrar as unidades significantes em um nível superior. Assim, forma e sentido são inseparáveis no funcionamento da língua e permitem as operações ascendentes e descentes entre os níveis linguísticos (BENVENISTE, 1989). Cardoso (2010) ressalta que a distinção entre os elementos constituintes e integrantes feita por Benveniste tem o objetivo de marcar o princípio fundamental que rege a relação entre as noções de forma e sentido na análise linguística. Essas noções "estão articuladas em toda a extensão da língua, estando relacionadas ao aspecto estrutural dos níveis e às funções de constituinte e integrante que representam" (CARDOSO, 2010, p. 50).

A noção de nível de análise está atrelada ao conceito de intersubjetividade formulado por Benveniste. A intersubjetividade está relacionada ao ato de enunciar, que implica assumir a posição de $e u$ no diálogo e, como consequência, implantar diante de si um $t u$. $E u$ é aquele que enuncia e $t u$ é aquele a que se dirige o enunciado, sendo essas posições recíprocas e reversíveis. O $e u$ deve abandonar sua posição para que o $t u$ possa assumi-la. Em outros termos, o $e u$ precisa marcar-se como $t u$, para que o $t u$ assuma a posição de $e u$ e enuncie. Essa mudança de posições permite que em um diálogo os sujeitos enunciem acerca de um assunto em comum, trocando ideias, pensamentos e opiniões.

As trocas que ocorrem em um diálogo entre $e u$ e $t u$ são norteadas pela busca da referência e da co-referência. Ao enunciar, o locutor refere por meio de seu discurso, possibilitando ao outro $(t u)$ co-referir identicamente. Ao marcar sua presença por meio 
da enunciação, o locutor faz com que cada instância de discurso constitua um centro de referência interno (BENVENISTE, 1988).

Nota-se que por meio das noções de referência e co-referência pode-se refletir acerca da construção de um diálogo estabelecido entre $e u$ e $t u$ em torno de um assunto. Kuhn (2006, p. 201, grifo da autora) descreve que o "tu demonstra a compreensão do que foi dito ao se dizer $e u$ e enunciar", assim "a co-referência não só garante o diálogo, mas também permite ao tu significar." Pode-se afirmar que em um diálogo busca-se a co-referência, que, além de ser própria da enunciação, marca a compreensão entre os interlocutores.

Com base nos conceitos explanados, percebe-se que a elucidação de uma noção benvenistiana implica o esclarecimento de outras. Isso se deve a estreita relação que há entre os conceitos dessa teoria linguística. Benveniste fornece uma rede de conceitos teóricos difícil de ser pensada de maneira segregada. Nota-se que ao vislumbrar-se a interligação entre os conceitos, obtém-se um embasamento teórico mais consistente, que possibilita refletir acerca do funcionamento da língua, inclusive nos casos de distúrbios de linguagem.

Tendo em vista a interligação conceitual explorada, neste estudo serão mostradas, por meio da análise linguística de um diálogo, em situação clínica, as implicações desses conceitos benvenistianos no processo de avaliação de linguagem. Destaca-se que, mesmo considerando-se a importância de todos os conceitos, o enfoque se voltará aos níveis de análise linguística.

\subsection{Diálogos da Linguística da Enunciação}

A Teoria Enunciativa de Benveniste, que integra a Linguística da Enunciação, vem sendo fonte de interlocução para várias áreas do conhecimento. Atualmente, existe uma variedade considerável de trabalhos que dialogam com essa teoria, seja sob um viés linguístico, seja sob um viés clínico.

$\mathrm{Na}$ área da linguística, pode-se citar Silva (2007), que inaugurou um novo campo de pesquisa ao abordar a aquisição de linguagem pelo viés da Teoria Enunciativa de Benveniste. No âmbito clínico, tem-se alguns estudos como o de Kuhn (2006), que investiga a construção da co-referência em dois casos de retardo de linguagem, analisando diálogos entre terapeuta-paciente, familiar-paciente e terapeuta-familiarpaciente.

Ainda sob uma perspectiva clínica, Oliveira (2011) faz uma reflexão teóricoconceitual sobre a relação linguagem-gagueira-falante, e Boeckel (2012) reflete sobre a prática da entrevista na clínica fonoaudiológica, embasando-se no conceito benvenistiano de intersubjetividade. Em outro estudo, Oliveira e Souza (2014) analisam, em dois sujeitos com distúrbio de linguagem, a importância de uma hipótese de funcionamento de linguagem com base nas relações de forma e sentido e de mecanismos e estratégias enunciativas. Em trabalho mais recente, Novello (2016) elabora uma reflexão teórica e clínica sobre a análise linguística na Clínica dos Distúrbios de Linguagem analisando a relação estabelecida entre terapeuta-paciente num caso de gagueira, embasando-se, também, na intersubjetividade.

Esses são apenas alguns exemplos de trabalhos que recorreram ao campo da Teoria da Enunciação de Benveniste para discutir e refletir questões da clínica. 


\subsection{A avaliação na clínica fonoaudiológica de linguagem}

$\mathrm{Na}$ clínica fonoaudiológica de linguagem, tradicionalmente, três momentos podem ser delimitados: a entrevista, a avaliação e a terapia propriamente dita. Embora acredite-se que esses momentos estão necessariamente sobrepostos (ARANTES, 1997), o interesse deste trabalho recai sobre a avaliação de linguagem.

O processo de avaliação de linguagem é um momento central na clínica, visto que a partir dele duas condições devem ser preenchidas: possibilitar o estabelecimento de uma distinção entre "normalidade" e "patologia" e promover um maior entendimento e caracterização de uma condição considerada patológica (ANDRADE, 2006). Este estudo irá centrar-se nos procedimentos adotados para a avaliação/caracterização de linguagem no fazer clínico fonoaudiológico.

$\mathrm{Na}$ fonoaudiologia podem ser observados diferentes métodos de avaliação de linguagem, cada qual elaborado a partir de subsídios de uma concepção teórica de linguagem distinta. Nesse sentido, entende-se que a forma de se realizar um processo de avaliação de linguagem está relacionada à concepção de linguagem adotada pelo clínico. Conforme afirma Hage (1997, p. 17), "a forma como a linguagem é concebida e utilizada pelo terapeuta traz consequências sobre sua maneira de conduzir suas avaliações e terapias".

Vê-se frequentemente fonoaudiólogos recorrerem a aparatos técnicos forjados no campo da linguística e da área conhecida como Aquisição da Linguagem. Nessa direção, Arantes (1997) aponta a existência de três modalidades de avaliação de linguagem empregadas na clínica fonoaudiológica: a inatista, a piagetiana e a pragmática. Na vertente inspirada na teoria inatista o paciente é submetido a uma bateria de testes e provas, onde a própria linguagem é saber prévio e necessário ao desempenho. Já na avaliação baseada nos estudos de Jean Piaget, observam-se as construções sensório-motoras da criança por meio de provas de cognição ou da organização do brincar. $O$ resultado da avaliação de caráter piagetiano revela o nível de desenvolvimento simbólico da criança, estabelecendo em que período do estágio de desenvolvimento cognitivo ela se encontra. Por isso, segundo os parâmetros considerados nessa modalidade de avaliação, quando há atraso no desenvolvimento cognitivo, esse é visto como o causador do quadro de atraso de linguagem. A terceira modalidade de avaliação, a pragmática, teve o seu surgimento influenciado pelos primeiros estudos interacionistas e considera a linguagem como uma extensão das condutas comunicativas da criança.

Segundo Zorzi e Hage (2004, p. 12), ao abordar-se a avaliação de linguagem, quatro procedimentos podem ser diferenciados: "testes linguísticos e psicolinguísticos, análise de amostra de linguagem espontânea e dirigida, escalas de desenvolvimento e observação comportamental". Os autores destacam que os dois primeiros têm o objetivo de verificar a organização dos diferentes níveis linguísticos, como o fonológico, o sintático, o semântico e o pragmático. Já os outros dois procedimentos podem ser utilizados com crianças desde o nascimento e consideram diversos aspectos do desenvolvimento infantil relacionados à linguagem.

Para Hage (1997), a forma clássica de avaliação de linguagem emprega testes formais que enfocam a linguagem como parte do processo de aprendizagem. Esses testes incluem a avaliação da recepção auditiva e visual, da memória sequencial auditiva e visual, do vocabulário, da estrutura gramatical, da fonoarticulação, entre outras. Os 
testes, ou protocolos, resultam, geralmente, em escores ou porcentagens. Hage (1997, p. 25) alerta para o fato de que essa "determinação de escores em linguagem quantifica uma capacidade mental humana altamente qualitativa que, por sua complexidade, não se evidencia em análises numéricas". Devido a isso, mesmo embasado em um protocolo, o terapeuta deve atentar a informações que somente seu olhar clínico permitirá obter, ou seja, as informações de caráter qualitativo, aquelas que escapam aos números. Os protocolos, por mais elaborados que sejam, nunca abrangerão todas as potencialidades comunicativas do paciente. Esse fato não pode ser negligenciado pelo terapeuta.

Ainda sobre o processo de avaliação na clínica, Hage (1997) observa que esse é um procedimento fragmentado e circunstancial, visto que a linguagem das pessoas não se revela em todos os seus usos e formas em apenas algumas sessões de atendimento fonoaudiológico. Esgotar o uso da linguagem do ser humano é impossível, pois mesmo criando-se um vasto número de situações de interlocução, com diferentes interlocutores, nunca se obterão todas as possibilidades e variedades comunicativas do indivíduo.

Como visto, os procedimentos de avaliação evidenciam uma concepção de linguagem que, consequentemente, reflete em uma prática clínica. Este trabalho trata da questão da avaliação de linguagem, adotando uma abordagem teórico-metodológica com filiação à Teoria da Linguística da Enunciação. Por meio dessa abordagem pretende-se discutir a noção de nível de análise linguística proposta por Émile Benveniste e as implicações dessa noção para a Clínica dos Distúrbios de Linguagem.

O sintagma Clínica dos Distúrbios de Linguagem se constitui como um lugar privilegiado para pensar-se na natureza do distúrbio de linguagem. De acordo com Cardoso (2010), essa concepção de clínica fornece um status diferenciado às manifestações de linguagem desviantes, pois não segrega o sujeito de seu sintoma de linguagem. Além disso, segundo Surreaux (2008) e Flores (2008), a Clínica dos Distúrbios de Linguagem considera o sintoma de linguagem como uma maneira singular de o sujeito estar na língua, não sendo possível separar o sintoma daquele que enuncia. Em direção semelhante, Novello (2016) ressalta que nessa forma de clínica tem-se um espaço em que o foco é o sujeito e não a patologia.

A partir dessa perspectiva, entende-se que a discussão sobre a análise de linguagem em casos de distúrbio de linguagem integra o processo de avaliação na clínica. O viés teórico-clínico adotado nesse trabalho propõe uma noção de nível de análise linguística que contempla a relação língua-linguagem-falante no processo de avaliação de linguagem.

\section{Metodologia}

O presente estudo possui delineamento qualitativo descritivo retrospectivo, segundo a classificação de Alves (2003). O método qualitativo objetiva entender o contexto em que algum fenômeno acontece e, por isso, permite observar vários elementos mutuamente em um grupo menor de indivíduos (VÍCTORA; KNAUTH; HASSEN, 2000). Este trabalho é vinculado à pesquisa "A análise enunciativa na clínica dos distúrbios de linguagem", registrada e aprovada pelo Comitê de Ética em Pesquisa do Instituto de Psicologia da Universidade Federal do Rio Grande do Sul (UFRGS), sob o número 20569.

Os dados deste estudo são oriundos de um atendimento fonoaudiológico de um paciente, sendo que esse foi gravado em forma de áudio. Previamente à coleta de dados, 
os responsáveis pelo participante assinaram o Termo de Consentimento Livre e Esclarecido, e o pesquisador responsável assinou o Termo de Compromisso de Utilização e Divulgação dos Dados. No item 4 será efetuada uma breve contextualização deste caso clínico.

Os dados obtidos serão apresentados por meio de um recorte enunciativo, que representa um fragmento da transcrição do diálogo estabelecido entre terapeuta (T) e paciente (P) em situação de atendimento fonoaudiológico. Com isso, o recorte enunciativo configura-se como a unidade de análise desse trabalho. A transcrição seguirá as diretrizes fornecidas por uma base teórica enunciativa e será realizada de acordo com a escrita gráfica tradicional, mantendo os traços de oralidade na sua apresentação, conforme o seguinte exemplo: "era um meninu piquenu!".

O recorte enunciativo será mostrado em forma de quadro, indicando no seu cabeçalho a contextualização da cena enunciativa. Os turnos de fala dos interlocutores serão numerados por algarismos arábicos, obedecendo a sequência de realização. Além disso, o quadro também conterá uma coluna destinada a comentários. A análise dos dados será exibida após o recorte enunciativo.

Destaca-se que, a partir do referencial teórico, elegeram-se as categorias de análise, que serão representadas pelas operações de seleção e combinação das unidades linguísticas. Essas duas operações serão analisadas na relação com os diferentes níveis da língua, buscando evidenciar as relações distribucionais e integrativas que compreendem a noção de nível de análise linguística proposta neste trabalho.

\section{Contextualizando o caso}

O caso clínico que integra essa pesquisa é de um paciente do sexo masculino (P), com 8 anos de idade no período da coleta dos dados, diagnosticado com distúrbio de linguagem. Esse paciente era atendido pela equipe de fonoaudiologia na Clínica de Atendimento Psicológico da Universidade Federal do Rio Grande do Sul.

$\mathrm{P}$ iniciou os atendimentos fonoaudiológicos com cerca de quatro anos de idade, sendo que a queixa principal de seus pais era a fala reduzida e de difícil compreensão. Essas características de fala citadas pelos pais confirmaram-se por meio das avaliações de linguagem efetuadas e, além disso, percebeu-se que $\mathrm{P}$ apresentava um comportamento anterior ao esperado para a sua idade, tendo pouco interesse pela interação e dificuldades em estabelecer uma brincadeira compartilhada.

Após um período de intervenções, houve avanços significativos na linguagem do paciente, que passou a demonstrar mais interesse em interagir com o outro, inclusive por meio do brincar. As evoluções se evidenciaram também pelo fato de $\mathrm{P}$ falar mais $\mathrm{e}$ buscar a compreensão por parte de seu interlocutor usando diferentes meios, como, por exemplo, o contexto da cena, gestos corporais e repetição e/ou reformulação da frase ou palavra, aspectos presentes no recorte enunciativo que será apresentado.

\section{Recorte enunciativo}

Quadro 1 - Recorte enunciativo 
Contextualização do diálogo: A terapeuta $(\mathrm{T})$ e o paciente $(\mathrm{P})$ exploravam uma das fichas com desenhos do manual Avaliação fonológica da criança ${ }^{4}$ (YAVAS; HERNANDORENA; LAMPRECHT, 1991). A proposta era que o paciente criasse uma história para a terapeuta escrever. A partir da proposta inicial, o diálogo foi desenvolvido. $\mathrm{O}$ trecho transcrito abaixo é uma parte do diálogo.

\begin{tabular}{|c|c|c|}
\hline Terapeuta & Paciente & Comentários \\
\hline $\begin{array}{l}\text { 5. Iiii, tu tá falandu muitu } \\
\text { rápidu, eu tô aqui ó... }\end{array}$ & 6. Ei! U qui é issu? & $\begin{array}{l}\text { T está escrevendo o que } \\
\mathrm{P} \text { lhe diz. } \\
\mathrm{P} \text { questiona a } \mathrm{T} \text {, } \\
\text { apontando para o trator } \\
\text { presente no desenho. }\end{array}$ \\
\hline $\begin{array}{l}\text { 7. Bah, essi daí só quem } \\
\text { mora na colônia sabi. }\end{array}$ & 8. Сo... & $\begin{array}{l}\text { P parece estar se } \\
\text { questionando sobre o } \\
\text { que seria "colônia". }\end{array}$ \\
\hline $\begin{array}{l}\text { 9. Lá na fazenda, sabi } \\
\text { comu é qui é u nomi disso } \\
\text { aí? }\end{array}$ & 10. Que? & \\
\hline 11. Trator. & 12. Te tem um tatoi. & \\
\hline $\begin{array}{l}\text { 13. Tu já viu um trator di } \\
\text { verdadi? }\end{array}$ & 14. Não, você faô. & \\
\hline 15. É lá na colônia. & $\begin{array}{l}\text { 16. Eu fi um issu. Eu vim } \\
\text { issu. Eu fi. }\end{array}$ & \\
\hline 17. U que qui tu viu? & $\begin{array}{l}\text { 18. Eu vi issu. É pem... Eu } \\
\text { fui numa fassenda. }\end{array}$ & $\begin{array}{l}\text { P aponta para o desenho } \\
\text { do trator. }\end{array}$ \\
\hline $\begin{array}{l}\text { 19. Tu foi numa fazenda? } \\
\text { I era longi da tua casa? }\end{array}$ & 20. É pem ongi. & \\
\hline $\begin{array}{l}21 . \text { I comu é qui tu foi? Di } \\
\text { carru, di a pé, di motu, di } \\
\text { avião... }\end{array}$ & 22. É. Tem uma canona. & \\
\hline $\begin{array}{l}\text { 23. Tu foi de carona... } \\
\text { Mas carona du quê? }\end{array}$ & 24. Um uma amigos. & \\
\hline $\begin{array}{l}\text { 25. Mas essis amigus } \\
\text { tavam di [carru], di } \\
\text { ônibus... }\end{array}$ & 26. [Sim.] & $\begin{array}{l}\text { Fala de } \mathrm{P} \text { sobreposta à } \\
\text { de } \mathrm{T} \text { na palavra carro. }\end{array}$ \\
\hline 27. Há tá! & 28. Eis tavam di carru. & \\
\hline
\end{tabular}

\section{Análise}

No início do recorte enunciativo transcrito, $\mathrm{P}$ notou o desenho de um trator, e indagou a T: "Ei! U qui é issu?" (6). Em 7, T falou que se tratava de algo que "quem

\footnotetext{
4 A Avaliação Fonológica da Criança é composta por fichas de desenhos e é um instrumento frequentemente usado na clínica fonoaudiológica para avaliar-se a linguagem dos pacientes.
} 
mora na colônia sabi". P apresentou estranhamento em relação à palavra "colônia", dizendo: "Co..." (8). T notou a incompreensão por parte de P, então substituiu a palavra "colônia" por "fazenda" (9). Ao fazer essa substituição, pode-se afirmar que P compreendeu a que local $\mathrm{T}$ estava se referindo, pois, posteriormente, ele afirmou ter visto um trator quando foi a uma fazenda $(16,18)$. Dessa forma, o sentido da frase dita por $\mathrm{T}$ em 7 , foi compreendido pela substituição no nível da palavra ("colônia" por "fazenda") e pela combinação na frase (9).

As palavras "colônia" e "fazenda" tiveram representações de sentido semelhantes para T, pois ela usou o termo "fazenda" para que $\mathrm{P}$ se apropriasse, de maneira aproximada, do sentido de "colônia" e conseguisse entender o local onde há trator. Sabe-se que cada termo possui um sentido distinto, porém, na língua em uso, a substituição é uma operação recorrente na busca pela co-referência.

$\mathrm{Na}$ passagem 16 são evidentes as operações de seleção/combinação que $\mathrm{P}$ realizou no uso da língua. São operações que incidem no nível fonemático, mas que não estão dissociadas dos níveis da palavra e da frase. Para selecionar as unidades linguísticas e combiná-las no sintagma, $\mathrm{P}$ recorreu aos processos de segmentação e substituição, fato evidenciado em "Eu fi um issu", em que há troca entre os fonemas $/ \mathrm{v} /$ e /f/. Na sequência, P reformulou-se, produzindo o /v/, porém acrescentando um $/ \mathrm{m} / \mathrm{na}$ palavra, o que, em termos semânticos, poderia mudar o sentido da mesma, pois a forma "vim" é reconhecida na língua e carrega consigo o sentido de "vir"; apesar disso, nesse diálogo, "vim" assume o significado de "ver" (vi). Isso só pode ser percebido ao considerar-se a relação de integração do elemento "vim" com os demais componentes da frase: "Eu vim issu". Além da integração desse elemento, há uma relação entre os turnos de fala que é essencial para a compreensão: trata-se da co-referência, ou seja, locutor e alocutário dialogam sobre algo em comum, fazendo trocas acerca do assunto.

Ainda em 16, P reformulou-se mais uma vez, dizendo: "Eu fi". Em 18, apontando para o desenho do trator, $\mathrm{P}$ finalmente conseguiu sintagmatizar as unidades significantes, produzindo o enunciado: "Eu vi issu". É fundamental destacar que o sintagma elaborado por $\mathrm{P}$ em 18 não foi construído somente a partir de operações linguísticas realizadas por ele, mas também por operações efetuadas por $\mathrm{T}$ na coreferência discursiva. T, a partir da fala de P em 16, diz: "U que qui tu viu?" (17). Ou seja, $\mathrm{T}$, diante do enunciado de $\mathrm{P}$, também recorreu aos processos de segmentação e de substituição de unidades linguísticas, integrando essas unidades em um nível superior e engendrando a frase do turno 17.

No segmento compreendido entre as passagens 21-28, observam-se as relações existentes entre as operações de seleção/combinação e a imbricação dos níveis da língua. A indagação formulada por T em 21 ("I comu é qui tu foi?") foi respondida por P com um sentido possível: "tem uma canona". Porém, a pergunta buscava saber o meio de transporte que $\mathrm{P}$ usou para se deslocar até a fazenda, tanto que $\mathrm{T}$ forneceu opções de resposta ("Di carru, di a pé, di motu, di avião..."). Na resposta de $\mathrm{P}$ em 22, observa-se a seleção o verbo "ter" ao invés do verbo "ir". T percebeu essa seleção e forneceu, em 23, uma possibilidade de substituição que tornaria o sintagma mais adequado: "Tu foi de carona". O que ocorreu foi a substituição do verbo "ter" pelo "ir" na fala da terapeuta.

Na sequência do diálogo, T insistiu na questão: "Mas carona du quê?". P então respondeu em 24 com: "Um uma amigos". A resposta de $\mathrm{P}$ direciona ao pensamento de que o segmento "du quê" (em 23) foi substituído por "com quem". Dessa maneira, P respondeu que foi com "Um uma amigos" (24). Nessa passagem (24), observam-se também as operações de seleção e de combinação realizadas por $\mathrm{P}$ na busca pela 
utilização adequada do artigo em relação ao substantivo (um, uma). Em 25, T seguiu interpretando o que $\mathrm{P}$ disse, buscando a co-referência e conduzindo ao enunciado de $\mathrm{P}$ em 28 ("Eis tavam di carru"). Assim, ao finalizar essa sequência de diálogo, o sentido da resposta de $\mathrm{P}$, em relação à pergunta formulada por T em 21 ("I comu é qui tu foi? Di carru, di a pé, di motu, di avião..."), pode ser apreendido como: "ele foi à fazenda de carro, de carona com uns amigos". Observa-se que esse segmento (21-28) mostra como os interlocutores buscam a co-referência ao enunciar, ou seja, a busca pelo sentido é o fio condutor do diálogo. Nessa busca, tanto $\mathrm{T}$ como $\mathrm{P}$ realizaram as operações de seleção e combinação dos elementos linguísticos em relação aos diferentes níveis da língua. Para isso, ambos necessitaram segmentar e substituir os elementos linguísticos, e integrá-los em um nível superior da língua. Todo esse movimento de análise e de operações enunciativas pode ser observado na imbricação dos diferentes níveis da língua. Seja, por exemplo, no nível do fonema em relação ao da palavra (ex: "canona", em 22 , em que há a seleção do fonema $/ \mathrm{n} /$ ao invés do / $/$ ), ou no nível da palavra em relação ao da frase (ex: "Um uma amigos", em 24, em que ocorre a seleção dos elementos "um" e "uma", ao invés de "uns" ou "alguns").

Com base na análise desenvolvida, pode-se afirmar que a terapeuta e o paciente recorreram às operações de distribuição e de integração dos elementos linguísticos (fonemas, morfemas, palavras, frases). Na busca da co-referência no discurso, o falante, nas posições de locutor/alocutário, segmenta e substitui as unidades da língua, e as integra em um nível superior.

\section{Os níveis de análise linguística na Clínica dos Distúrbios de Linguagem}

A trajetória desenvolvida no presente trabalho se inicia com a contextualização do tema e a apresentação de três objetivos. O primeiro deles consiste em refletir sobre a noção de nível de análise linguística e suas implicações na avaliação de linguagem na Clínica dos Distúrbios de Linguagem. Para alcançar esse objetivo foi necessário contextualizar-se a Teoria Enunciativa benvenistiana, bem como a noção de nível de análise linguística que a integra. Outros conceitos dessa teoria também foram explorados devido à relação estabelecida entre eles.

A discussão acerca da avaliação na clínica fonoaudiológica de linguagem se configura como o segundo objetivo do estudo. Ao realizar-se uma pesquisa a respeito da mesma, constatou-se que, de acordo com a concepção teórica de linguagem adotada, há diferentes formas de se avaliar. Dessa maneira, verificou-se que é essencial haver um embasamento teórico sólido para avaliar e intervir na Clínica dos Distúrbios de Linguagem.

O terceiro objetivo do trabalho é mostrar e descrever a imbricação dos níveis da língua. Para isso, além do esclarecimento teórico dessa noção benvenistiana, mostrou-se a imbricação dos níveis da língua por meio da análise de linguagem de um diálogo em contexto clínico.

No recorte enunciativo analisado, pode-se perceber que as categorias de análise deste estudo, ou seja, as operações de seleção e de combinação, mostraram a particularidade do funcionamento dialógico construído por T e P. Por meio dessas operações se evidenciam as relações sintagmática e paradigmática, que se referem, respectivamente, à combinação e à seleção/substituição dos elementos linguísticos. As operações de seleção e de combinação ocorrem nos diferentes níveis da língua, e podem 
ser exemplificadas em diferentes passagens do recorte enunciativo apresentado. No nível do fonema, pode-se citar a fala de $\mathrm{P}$ nos turnos 16 e 18, e, no nível da palavra, tem-se a fala de $\mathrm{T}$ em 7 e em 9 . Nesses trechos percebe-se que a seleção e a combinação de elementos linguísticos em um nível mais inferior da língua têm repercussões nos níveis mais superiores, fato que comprova que o funcionamento linguístico se dá de maneira imbricada. Em outros termos, ao constatar-se que as modificações em um nível inferior da língua repercutem nos níveis superiores, percebe-se que há uma estreita relação entre os diferentes níveis da língua e que o funcionamento dos mesmos é integrado.

Cardoso (2010), ao propor a noção de nível de análise linguística como princípio de análise na Clínica dos Distúrbios de Linguagem, afirma que quando ocorrem alterações no nível da palavra, mesmo mantendo-se o nível da frase "preservado", o entendimento do discurso pode ficar prejudicado, pois o sentido dos enunciados é construído no encadeamento dos níveis, e um problema no nível mais inferior afeta os níveis superiores. Com isso, o autor argumenta que o funcionamento do componente compreensivo ocorre de maneira "ascendente". Pode-se dizer que o termo ascendente é empregado para caracterizar certo grau de dificuldade na compreensão do enunciado, que aumenta ao avançar-se para os níveis superiores da língua.

Considerando-se a ascendência descrita por Cardoso (2010), destaca-se que na análise efetuada não se observou uma sistematicidade entre a alteração em um determinado nível da língua e a respectiva compreensão do enunciado. Ou seja, não se pode afirmar que a compreensão é facilitada quando a alteração está mais evidente no nível da palavra, e dificultada quando está no nível da frase. O que se observou na análise do diálogo foi que a frase, por ser o nível mais superior da língua, possibilita a integração de todos os elementos linguísticos, fornecendo um contexto que pode favorecer a compreensão. Para exemplificar isso, tem-se a enunciação de $\mathrm{P}$ em 20 , em que, por meio da combinação das palavras em um nível superior, foi possível compreender o que ele disse com a frase "é pem ongi" (é bem longe). Se fosse observado apenas o nível da palavra, possivelmente a compressão seria dificultada. Portanto, ressalta-se que não há uma previsibilidade no que tange ao aspecto compreensivo da língua. A alteração pode se manifestar em qualquer nível da língua, seja inferior ou superior, mas o que definirá se haverá ou não compreensão será a relação estabelecida entre locutor e interlocutor, no espaço e tempo (aqui e agora) em que se realiza a enunciação.

A noção de nível de análise linguística empreendida neste trabalho implica os conceitos de forma e sentido. Afinal, como elucidado no item 2.1, a forma de uma unidade linguística está relacionada a sua capacidade de ser dissociada em elementos constituintes de nível inferior, enquanto o sentido é a capacidade de integração em um nível superior. Nesse contexto, ao realizar-se a substituição em um nível da língua, altera-se tanto a forma, quanto o sentido da unidade linguística. Ilustrando a associação entre as operações supracitadas e as noções de forma e sentido, tem-se o trecho entre 16 e 18, em que P, para conseguir produzir a forma "vi", segmentou e substituiu mais de uma vez. Inicialmente, P falou "eu fi", reformulando-se e enunciando, em seguida, "eu vim", para apenas em 18 conseguir dizer "eu vi”. Em todas as reformulações destacadas constata-se que as operações de seleção e combinação alteraram a forma e o sentido da unidade linguística, mostrando que há uma relação entre esses conceitos. Nota-se que P usou essas operações como um recurso para conseguir ser compreendido por $\mathrm{T}$, pois houve reformulações até a forma remeter ao sentido desejado. 
A busca pela compreensão, exibida nas reformulações de $\mathrm{P}$, ocorreu por conta de sua vontade em se fazer entendido e, também, pelas intervenções de T. Por possuir um distúrbio de linguagem, $\mathrm{P}$ tende a ter mais dificuldade ao realizar as operações de segmentação e substituição, pois elas demandam do sujeito a percepção das alterações na produção de sua fala. É dessa maneira que a compreensão do diálogo é influenciada pela intersubjetividade estabelecida entre os interlocutores, afinal essa noção é própria do ato de enunciar. É no processo de intersubjetividade que o sujeito assume a posição de $e u$ e, ao enunciar, implanta diante de si um $t u$. No recorte enunciativo transcrito, é nítido que a intersubjetividade estabelecida entre $\mathrm{P}$ e $\mathrm{T}$ permitiu a ambos a demonstração de desentendimentos e a reformulação dos enunciados, o que marca a busca dos dois pela referência e pela co-referência na enunciação.

A co-referência é elaborada com base na referência fornecida pela enunciação do $e u$. Quando há algum problema no entendimento do enunciado, a troca entre os interlocutores é prejudicada, e a co-referência não ocorre conforme o esperado. É nesse contexto de incompreensão que o locutor recorre a reformulações nos níveis da língua para fornecer subsídios para o outro co-referir. Esse processo pode ser visto entre os turnos 18 e 20, em que $\mathrm{P}$ relatou ter visto algo e apontou para o desenho do trator (18). Nesse turno, $P$ iniciou e não concluiu a frase: "É pem... Eu fui numa fassenda". T atentou-se e buscou entender a relação entre o que foi dito por P, co-referindo em 19 com as interrogações: "Tu foi numa fazenda? I era longi da tua casa?". Assim, P confirmou em 20: "É pem ongi”, fornecendo para $T$ as informações necessárias para o diálogo ter continuidade.

Com base nos apontamentos expostos, afirma-se que a atuação fonoaudiológica em casos de distúrbio de linguagem suscita inquietações acerca do processo de avaliação de linguagem a ser adotado pelo terapeuta. Essas inquietações são representadas por meio dos objetivos propostos no trabalho.

A discussão em torno da avaliação de linguagem mostrou a necessidade de uma fundamentação teórica que contemplasse a relação entre o falante e a língua, elegendose, assim, a noção de nível de análise linguística presente na Teoria Enunciativa de Benveniste. Por se tratar de uma teoria oriunda da Linguística da Enunciação, teve-se que construir uma metodologia que possibilitasse mostrar e descrever a imbricação dos níveis da língua em um caso de distúrbio de linguagem. Através da metodologia apresentada na análise de linguagem, foi possível refletir sobre a noção de nível de análise linguística e suas implicações na avaliação de linguagem na clínica fonoaudiológica. Dessa maneira, atingiu-se integralmente os objetivos do estudo.

\section{Conclusões}

Conclui-se que o processo de avaliação se configura como um momento central na clínica, sendo sustentado por diferentes teorias que originam métodos distintos de se avaliar no campo da fonoaudiologia. Este trabalho procurou mostrar a instância de avaliação como um espaço em que a linguagem constitui o sujeito falante, tendo como base a Teoria Enunciativa de Benveniste. Por meio dessa vertente teórica, é possível analisar e compreender o funcionamento de linguagem de cada sujeito, aspecto extremamente relevante para a prática clínica do fonoaudiólogo frente aos distúrbios de linguagem. Embora a noção de nível de análise linguística tenha recebido atenção especial, o fenômeno da intersubjetividade e a busca pela co-referência também são 
aspectos considerados na relação terapeuta-paciente. No recorte enunciativo analisado, pôde-se observar que o conceito de intersubjetividade, representado pelo dispositivo $\mathrm{eu}$ $t u$, é fundamental na clínica. Na cena, o instrumento de avaliação, composto por fichas com desenhos, serviu como meio para que os interlocutores pudessem referir e coreferir no diálogo. Esse fato, além de evidenciar que a intersubjetividade está relacionada ao ato de enunciar, que implica assumir a posição de eu no diálogo, mostra a sobreposição entre os momentos de entrevista, avaliação e tratamento na clínica. Essa constatação indica que nos processos de avaliação e de entrevista as intervenções também estão presentes; afinal, ao se avaliar, já está se tratando o paciente.

O trabalho até aqui desenvolvido sustenta que a Teoria da Enunciação de Benveniste é relevante para a Clínica dos Distúrbios de Linguagem por, de forma diferente de outras abordagens, considerar tanto o que é enunciado pelo paciente, como o que é enunciado pelo terapeuta. Dessa forma, a análise de linguagem, além de reconhecer a imbricação dos níveis da língua, prioriza a relação estabelecida entre locutor e interlocutor, no espaço e tempo (aqui e agora) em que se realiza a enunciação.

Destaca-se que cabe ao terapeuta estudar e conhecer a teoria que o norteará, pois a mesma influenciará em sua atuação profissional e terá repercussões no processo terapêutico. Além de dominar a base teórica, o terapeuta deve refletir sobre como relacionar teoria e prática de forma coerente. Por fim, ressalta-se que o campo de estudos em que se insere esse trabalho deve seguir sendo explorado para que se ampliem as contribuições da Linguística da Enunciação para a fonoaudiologia.

\section{REFERÊNCIAS}

ALVES, Magda. Como escrever teses e monografias: um roteiro passo a passo. Rio de Janeiro: Editora Campus, 2003.

ANDRADE, Lourdes. Procedimentos de avaliação de linguagem na clínica fonoaudiológica: entre o singular e o universal. In: LIER-DE VITTO, Maria Francisca; ARANTES, Lúcia (Org.). Aquisição, patologias e clínica de linguagem. São Paulo: Editora PUCSP, 2006.

ARANTES, Lúcia. O fonoaudiólogo, este aprendiz de feiticeiro. In: LIER-DE VITTO, Maria Francisca (Org.). Fonoaudiologia: no sentido da linguagem. $2^{a}$. ed. São Paulo: Editora Cortez, 1997.

BENVENISTE, Émile. Problemas de linguística geral I. Campinas: Pontes, 1989. O aparelho formal da enunciação. In: Problemas de Linguística Geral II. Campinas: Pontes, 1988. p. 81-92.

BOECKEL, Caroline. A entrevista como um dispositivo clínico na fonoaudiologia: um lugar de intersubjetividade. 2012. 92f. Trabalho de Conclusão de Curso (Graduação em Fonoaudiologia) - Faculdade de Odontologia, Instituto de Psicologia, UFRGS, Porto Alegre, RS.

CARDOSO, Jefferson Lopes. Princípios de análise enunciativa na clínica dos distúrbios de linguagem. 2010. 102f. Tese (Doutorado em Teorias do Texto e do Discurso) - Instituto de Letras, UFRGS, Porto Alegre, RS.

FLORES, Valdir do Nascimento. Das relações entre a linguística da enunciação e o estudo da fala sintomática. In: GRAÑA, C. G. Quando a fala falta: fonoaudiologia, linguística e psicanálise. São Paulo: Casa do Psicólogo, 2008. 
A enunciação e os níveis de análise linguística em dados de distúrbios de linguagem. Organon - Revista do Instituto de Letras da UFRGS, Porto Alegre, v. 29, n. 46, p. 177-190, jan./jun. 2009.

FLORES, Valdir do Nascimento; TEIXEIRA, Marlene. Introdução à Linguística da Enunciação. São Paulo: Editora Contexto, 2005.

HAGE, Simone Rocha de Vasconcellos. Avaliando a linguagem na ausência de oralidade: estudos psicolinguísticos. Bauru: EdUSC, 1997.

KUHN, Tanara Zingano. Enunciação e sintoma de linguagem: por um estudo sobre a construção da co-referência em casos de retardo de linguagem. Organon - Revista do Instituto de Letras da UFRGS, Porto Alegre, v. 20, n. 40/41, p. 179-214, jan./dez. 2006.

NOVELLO, Maiara. A intersubjetividade e a clínica dos distúrbios de linguagem: um caso de gagueira. 2016. 53f. Trabalho de Conclusão de Curso (Graduação em Fonoaudiologia) - Faculdade de Odontologia, Instituto de Psicologia, UFRGS, Porto Alegre, RS.

OLIVEIRA, Fabiana de. Aspectos enunciativos da relação falante, linguagem e outro na gagueira. 2011. 154f. Tese (Doutorado em Teorias do Texto e do Discurso) Instituto de Letras, UFRGS, Porto Alegre, RS.

OLIVEIRA, Luciéle Dias; SOUZA, Ana Paula Ramos. O distúrbio de linguagem em dois sujeitos com risco para o desenvolvimento em uma perspectiva enunciativa do funcionamento de linguagem. Rev. CEFAC, São Paulo, v.16, n. 5, p. 1700-1712, set./out. 2014.

SILVA, Carmen Luci da Costa. A instauração da criança na linguagem: princípios para uma teoria enunciativa em aquisição de linguagem. 293f. 2007. Tese (Doutorado em Teorias do Texto e do Discurso) - Instituto de Letras, UFRGS, Porto Alegre, RS.

SURREAUX, Luiza Milano. Sobre o Sintoma na Clínica de Linguagem. In: GRAÑA, C. G. Quando a fala falta: fonoaudiologia, linguística e psicanálise. São Paulo: Casa do Psicólogo, 2008.

VÍCTORA, Ceres Gomes; KNAUTH, Daniela Riva; HASSEN, Maria de Nazareth Agra. Pesquisa qualitativa em saúde: uma introdução ao tema. Porto Alegre: Tomo Editorial, 2000.

YAVAS, Mehmet; HERNANDORENA, Carmen Matzenauer; LAMPRECHT, Regina Ritter. Avaliação Fonológica da Criança. Porto Alegre: Artmed, 1991.

ZORZI, Jaime Luiz; HAGE, Simone Rocha de Vasconcellos. PROC Protocolo de Observação Comportamental: Avaliação de linguagem e aspectos cognitivos infantis. São Paulo: Editora Pulso, 2004. 